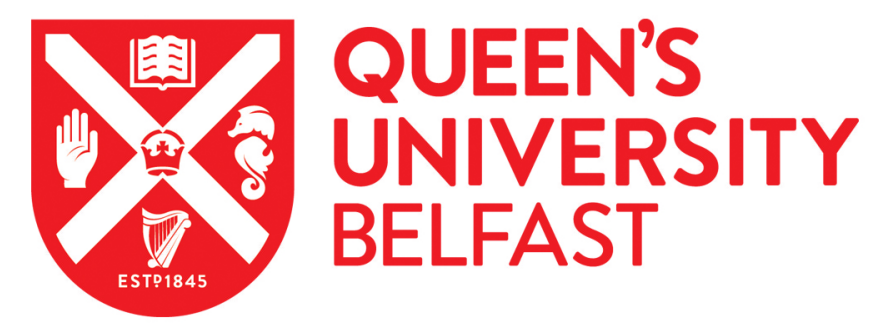

\title{
Influence of temperature on the anisotropic cutting behaviour of single crystal silicon: A molecular dynamics simulation investigation
}

Chavoshi, S. Z., Goel, S., \& Luo, X. (2016). Influence of temperature on the anisotropic cutting behaviour of single crystal silicon: A molecular dynamics simulation investigation. Journal of Manufacturing Processes, 23, 201-210. https://doi.org/10.1016/j.jmapro.2016.06.009

Published in:

Journal of Manufacturing Processes

Document Version:

Peer reviewed version

Queen's University Belfast - Research Portal:

Link to publication record in Queen's University Belfast Research Portal

Publisher rights

(C) 2016 Elseiver Ltd.

This manuscript version is made available under the CC-BY-NC-ND 4.0 license http://creativecommons.org/licenses/by-nc-nd/4.0/which permits distribution and reproduction for non-commercial purposes, provided the author and source are cited.

\section{General rights}

Copyright for the publications made accessible via the Queen's University Belfast Research Portal is retained by the author(s) and / or other copyright owners and it is a condition of accessing these publications that users recognise and abide by the legal requirements associated with these rights.

Take down policy

The Research Portal is Queen's institutional repository that provides access to Queen's research output. Every effort has been made to ensure that content in the Research Portal does not infringe any person's rights, or applicable UK laws. If you discover content in the Research Portal that you believe breaches copyright or violates any law, please contact openaccess@qub.ac.uk. 


\title{
Influence of temperature on the anisotropic cutting behaviour of single crystal silicon: A molecular dynamics simulation investigation
}

\author{
Saeed Zare Chavoshi ${ }^{1}$, Saurav Goel $^{2}$, Xichun Luo $^{1 *}$ \\ ${ }^{1}$ Centre for Precision Manufacturing, Department of Design, Manufacture and Engineering \\ Management, University of Strathclyde, Glasgow, G1 1XJ, UK \\ ${ }^{2}$ School of Mechanical and Aerospace Engineering, Queen's University, Belfast, BT9 5AH, \\ UK \\ *Corresponding author: xichun.luo@strath.ac.uk
}

\begin{abstract}
Using molecular dynamics (MD) simulation, this paper investigates anisotropic cutting behaviour of single crystal silicon in vacuum under a wide range of substrate temperatures ( $300 \mathrm{~K}, 500 \mathrm{~K}, 750 \mathrm{~K}, 850 \mathrm{~K}, 1173 \mathrm{~K}$ and $1500 \mathrm{~K}$ ). Specific cutting energy, force ratio, stress in the cutting zone and cutting temperature were the indicators used to quantify the differences in the cutting behaviour of silicon. A key observation was that the specific cutting energy required to cut the (111) surface of silicon and the von Mises stress to yield the silicon reduces by $25 \%$ and $32 \%$, respectively, at $1173 \mathrm{~K}$ compared to what is required at $300 \mathrm{~K}$. The room temperature cutting anisotropy in the von Mises stress and the room temperature cutting anisotropy in the specific cutting energy (work done by the tool in removing unit volume of material) were obtained as $12 \%$ and $16 \%$ respectively. It was observed that this changes to $20 \%$ and $40 \%$, respectively, when cutting was performed at $1500 \mathrm{~K}$, signifying a very strong correlation between the anisotropy observed during cutting and the machining temperature. Furthermore, using the atomic strain criterion, the width of primary shear zone was found to vary with the orientation of workpiece surface and temperature i.e. it remains narrower while cutting the (111) surface of silicon or at higher machining temperatures. A major anecdote of
\end{abstract}


the study based on the potential function employed in the study is that, irrespective of the cutting plane or the cutting temperature, the state of the cutting edge of the diamond tool did not show direct diamond to graphitic phase transformation.

Keywords: Molecular dynamics; Single crystal silicon; Anisotropy; Cutting temperature

\section{Introduction}

On account of its excellent stability, wear resistance, abundance and capability to form better oxides, silicon has been a consummate choice for optoelectronics, semiconductor and tribological applications [1]. Nanometric cutting, a sub-set of ultra-high precision manufacturing, can be employed for scalable manufacturing of single crystal silicon for producing 3D components requiring submicron form accuracy and nanometric smooth finish. However, bulk wafers of single crystal silicon exhibit poor machinability at room temperature due to its relatively low fracture toughness and high nanoindentation hardness, i.e. $0.9 \mathrm{MPa} \cdot \mathrm{m}^{1 / 2}$ and $9.8 \mathrm{GPa}$ [2] respectively on the (100) family of planes. A common understanding about silicon is that high temperature reduces the yield strength and hardness, and improves the fracture toughness which in turn improves its plastic deformation. However, its extent has never been reported and is crucial to advance our understanding to augment improved hybrid machining measures like laser assisted hot machining of silicon. An experimental study on this, aside from being troublesome, is surrounded by instrumental limitations. Therefore, molecular dynamics (MD) is an alternative choice for the investigation of minute details of such non-trivial cutting mechanisms [3]. The previous work on nanoscale machining by MD simulation has primarily focused on demystifying the material removal mechanisms at room temperature and only rudimentary work has been done so far on studying hot machining. In a preliminary investigation, the authors [4] compared hot machining of single crystal silicon carbide (3C-SiC) at $1200 \mathrm{~K}$ with cutting at $300 \mathrm{~K}$. As 
expected, hot machining was found to reduce the machining energy required to cut $3 \mathrm{C}-\mathrm{SiC}$ on a specific cutting orientation. Fang et al. [5] and Liu et al. [6] performed MD simulations to examine the variation in Young's modulus, hardness and elastic recovery of copper, diamond and gold during nanoindentation at high temperatures (up to $600 \mathrm{~K}$ ). They concluded that Young's modulus, hardness and the extent of elastic recovery (spring back) decreases with an increase of temperature. Hsieh et al. [7] used MD to investigate the effect of temperature on maximal normal forces and elastic recovery during nanoindentation of copper. They reported reduction in the aforementioned parameters with an increase in the substrate temperature. Lund et al. [8] experimentally investigated the effect of temperature during nanoindentation of pure platinum. They reported that the transition from elastic to plastic deformation takes place at progressively lower stress levels as temperature is increased. In a similar work, Domnich et al. [9] carried out high-temperature nanoindentation using Berkovich probe and observed that until a certain critical temperature $(623 \mathrm{~K})$, the nanoindentation hardness of silicon is dictated by the pressure required to transform the semiconducting $\mathrm{Si}$-I phase into the metallic $\mathrm{Si}$-II phase of silicon. However, no phase transformation was observed above $623 \mathrm{~K}$ and it was suggested that the nanoindentation hardness in silicon above $623 \mathrm{~K}$ is dictated by dislocation glide.

While there has been a modicum of success achieved on the understanding of high temperature nanoindentation behaviour, the area of high temperature nanometric cutting is relatively unexplored. It may be argued that both techniques are helpful in understanding and characterizing the materials, however, nanometric cutting unlike nanoindentation is a deviatoric stress-dominative process carrying pronounced component of shear [10]. The authors would like to point out that the elevated temperatures would cause accelerated dissolution-diffusion and adhesion wear of the diamond tool [11] and the role of environment will be even more vital during experiments, however, being a preliminary work in this 
direction, this study should only be seen as a test bed with the follow-on work aiming to address these points as well. Furthermore, to the best of the author's knowledge, hot machining of silicon in light of its anisotropic deformation has never been reported before. Accordingly, the present study aims to use MD simulation to investigate hot machining of single crystal silicon on the (010), (110) and (111) crystallographic orientations at a range of cutting temperatures, i.e. $300 \mathrm{~K}, 500 \mathrm{~K}, 750 \mathrm{~K}, 850 \mathrm{~K}, 1173 \mathrm{~K}$ and $1500 \mathrm{~K}$.

It may also be noted that a multifaceted interplay of different variables such as adhesive force, interfacial energy, anisotropy, contact area, number of dangling bonds, nanoscale friction etc. changes with the temperature and crystallographic orientation. More importantly, the lack of a robust potential energy function to simulate elevated temperature contact loading processes of silicon is still a key problem. This is perhaps the reason that most of the atomic scale simulation studies on silicon using the MD simulation have been performed at low temperatures [1, 12]. From the available literature, the two appropriate three body potentials which were evaluated for their use in this study are an analytical bond order potential (ABOP) [13] and a modified version of Tersoff potential [14]. The unique employability of these two potential functions was based on the fact that they both permit the interactions between silicon atoms (workpiece) and the carbon atoms (diamond cutting tool). Moreover, ABOP is known to be robust in accurately describing the bulk and dimer properties of silicon with a poor prediction of melting point while the later was developed to overcome the shortcomings of the original Tersoff potential function [15-16] to correctly describe the melting point and thermal softening behaviour of silicon at elevated temperatures. Although from a recent study made by the author's it is known that the modified version of the Tersoff variant underestimates the value of elastic modulus of silicon [17], it was still not known whether the material removal phenomena at high temperatures can be modelled appropriately and hence, following important research questions were 
identified as the missing gaps in the literature:

1- In the absence of a robust potential that could correctly describe the melting point as well as the brittle-ductile transition in silicon, can the variant proposed by Agrawal et al. [14] be used to study structural deformation of silicon at elevated temperatures during nanometric cutting?

2- How does the anisotropy of silicon vary during contact mode machining at elevated temperatures?

3- How does the material removal phenomenon changes at elevated temperatures?

4- How do the cutting indicators like specific cutting energy, friction coefficient, machining stress and cutting temperature varies during hot machining of silicon?

5- What is the fate of the cutting edge of the diamond tool during hot machining?

\section{Simulation methodology}

\subsection{Description of the nanometric cutting model}

The three-dimensional nanometric cutting model of silicon (the free-body diagram shown is basically a plane-stress representation of actual machining operation) has been illustrated in Fig. 1 in accord with the previously published studies [18-22]. In this simulation model, silicon workpiece and the diamond cutting tool were both modelled as deformable bodies. The region of atoms in the tool and the workpiece were divided into three zones namely, boundary atom zone, thermostatic atom zone and Newtonian atom zone. The boundary atoms were held rigid to reduce the boundary effects and to maintain the symmetry of the lattice. The Newtonian region was allowed to follow the Newtonian dynamics (LAMMPS NVE dynamics) while the thermostat zone was allowed to follow Berendsen thermostatic dynamics (LAMMPS NVT dynamics) in accord with the previously published studies to emulate the effect of heat carriers like chips and lubricants [23]. In order to minimize the boundary effects 
and to avoid significant heat transfer between the thermostat layer and the cutting region, the length and height of the substrate were chosen to be sufficiently large.

Fig. 1 also shows the force components along the $x, y$ and $z$ directions referred to as tangential cutting force or friction force $\left(F_{c}\right)$, thrust force or normal force $\left(F_{t}\right)$ and axial force $\left(F_{z}\right)$, respectively. It may be noted that $F_{z}$ is being introduced here only for awareness; however since the simulation model is assumed to be a plane-stress condition, the average magnitude of $F_{z}$ during cutting is expected to be zero.

The cutting resistance in general is indicated by the term called as "specific cutting energy". The specific cutting energy " $u$ " expressed in $\mathrm{N} / \mathrm{m}^{2}$ or $\mathrm{J} / \mathrm{m}^{3}$, is defined as the work done by the cutting tool in removing the unit volume of material and is expressed as:

$$
u=\frac{R \times v_{c}}{b \times t \times v_{c}}
$$

where $R$ is the resultant force in $\mathrm{nN}$ equals to $\operatorname{sqrt}\left(F c^{2}+F t^{2}\right)$ in plane-stress condition, $v_{c}$ is the cutting velocity $(\mathrm{m} / \mathrm{s}), b$ is the width of cut $(\mathrm{nm})$ and $t$ is the uncut chip thickness $(\mathrm{nm})$ or cutting depth (in plane-stress condition). 


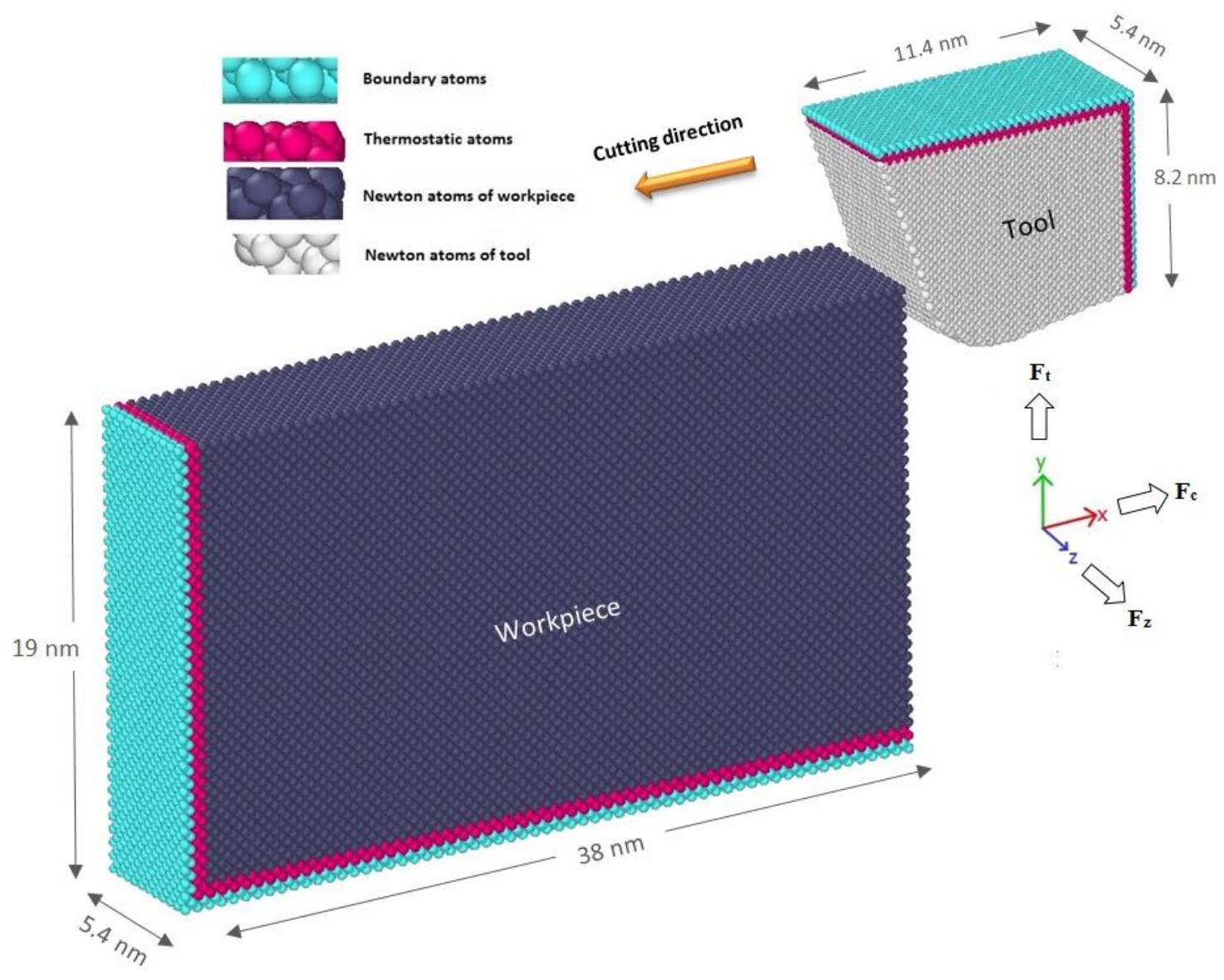

(a)

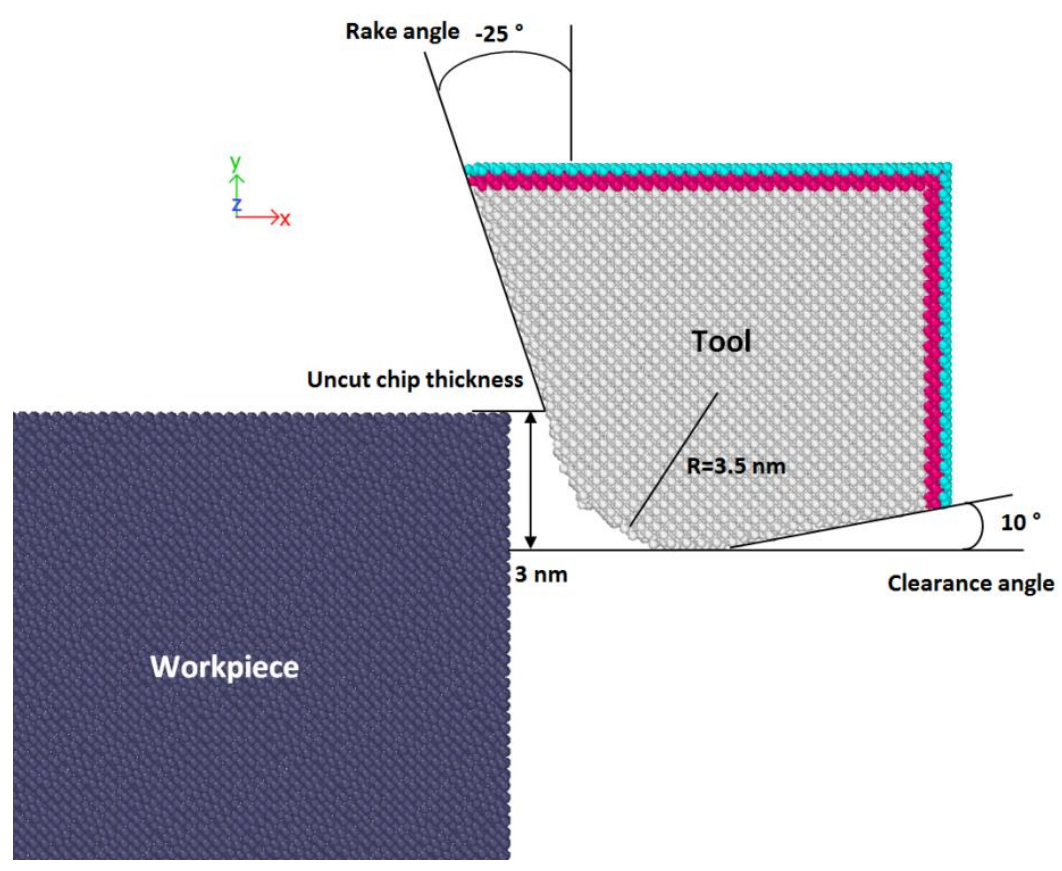

(b)

Fig. 1. Schematic of the MD simulation model 


\subsection{Potential energy function}

Selection of a potential energy function is crucial to obtain meaningful results from an MD simulation. Pair potentials such as Lennard-Jones or Morse have long been used in the past but they fail to predict the correct Cauchy pressure. Also, study of wear, fracture and plasticity involves reconfiguration of chemical bonds and unlike simple metals, this becomes even more complex situation in a diamond cubic material like silicon. Therefore, a threebody potential is a minimal choice for the purpose of studying nanometric cutting. The most popular bond order potential function for simulating silicon has been the Tersoff potential function [15-16] but in our case, Tersoff is not appropriate in its original formulation as it fails to correctly predict the melting point and the dimer properties of silicon such as binding energy, $D_{0}$, the equilibrium bonding distance, $r$, and the wave number, $k$, of the ground-state oscillation. One such shortcomings i.e. description of correct dimer properties was overcome by the analytical bond order potential (ABOP) proposed by Erhart and Albe [13], while the other drawback of correct prediction of melting point was addressed by Agrawal et al. [14] through a modified parameterisation of Tersoff potential function, however its robustness to predict the mechanical properties are yet to be explored which will be done in this paper through a simple test of elastic constants. We then used an appropriate potential for reporting rest of the simulation results of nanometric cutting.

\subsection{MD modelling and simulation methodology}

The simulations were performed at six distinct temperatures $(300 \mathrm{~K}, 500 \mathrm{~K}, 750 \mathrm{~K}, 850 \mathrm{~K}$, $1173 \mathrm{~K}$ and $1500 \mathrm{~K}$ ). To achieve precise simulation results, the corresponding equilibrium lattice constants were used readily to model the workpiece and the cutting tool. The cohesive energy corresponding to the equilibrium lattice constant of silicon obtained from the simulation at different temperatures for both the potential energy functions has been shown in 
Table 1 which is compared with the experimental values. The equilibrium lattice constant of diamond (cutting tool) at $300 \mathrm{~K}$ used during the simulations was $3.563 \AA$ for the ABOP [13] and periodic boundary conditions were used along the $z$ direction in all the simulations.

Table 1. Calculated equilibrium lattice constants and cohesive energy of single crystal silicon at different temperatures using $\mathrm{ABOP}$ [13] and modified Tersoff [14] potential energy functions

\begin{tabular}{|c|c|c|c|c|c|}
\hline Temperature (K) & $\begin{array}{c}\text { Modified } \\
\text { Tersoff } \\
\text { lattice } \\
\text { constant }(\AA)\end{array}$ & $\begin{array}{c}\text { Modified } \\
\text { Tersoff } \\
\text { cohesive } \\
\text { energy (eV) }\end{array}$ & $\begin{array}{c}\text { ABOP } \\
\text { lattice } \\
\text { constant } \\
(\AA)\end{array}$ & $\begin{array}{c}\text { ABOP } \\
\text { cohesive } \\
\text { energy (eV) }\end{array}$ & $\begin{array}{c}\text { Experimental } \\
\text { lattice constant } \\
(\AA)\end{array}$ \\
\hline 300 & 5.436 & -4.628 & 5.433 & -4.627 & 5.431 \\
\hline 500 & 5.439 & -4.627 & 5.436 & -4.626 & 5.434 \\
\hline 750 & 5.443 & -4.626 & 5.439 & -4.625 & 5.439 \\
\hline 850 & 5.444 & -4.625 & 5.441 & -4.624 & - \\
\hline 1173 & 5.449 & -4.623 & 5.446 & -4.623 & 5.449 \\
\hline 1500 & 5.454 & -4.622 & 5.451 & 4.620 & 5.457 \\
\hline
\end{tabular}

During the equilibration process, the diamond tool was kept $10 \AA$ ( $1 \mathrm{~nm})$ far from the substrate to avoid the interaction between silicon atoms (workpiece) and the carbon atoms (diamond tool). The model was allowed to run for $30 \mathrm{ps}$ to achieve the desired equilibration temperature. Further details of the simulation parameters are given in Table 2.

In this work, although HPC was employed, yet, the realistic cutting speeds ( 1 to $2 \mathrm{~m} / \mathrm{s}$ ) would have needed long computation times and therefore, $50 \mathrm{~m} / \mathrm{s}$ was chosen as an optimal cutting speed to run a large set of simulation trials presented in this work. In order to perform the simulations, a public-domain computer code, known as "large-scale atomic/molecular massively parallel simulator" (LAMMPS) [25] was used in conjunction with Open Visualization Tool (OVITO) [26] to visualise and to post-process the MD simulation data.

Table 2. Details of the MD simulation model and the cutting parameters used in the study

\begin{tabular}{|l|l|}
\hline Workpiece material & Single crystal silicon \\
\hline
\end{tabular}




\begin{tabular}{|c|c|}
\hline Workpiece dimensions & $38 \times 19 \times 5.4 \mathrm{~nm}$ \\
\hline Tool material & Single crystal diamond \\
\hline Cutting edge radius (tip radius) & $3.5 \mathrm{~nm}$ \\
\hline Uncut chip thickness (cutting depth in 2D) & $3 \mathrm{~nm}$ \\
\hline Cutting orientation and cutting direction & $\begin{array}{l}\text { Case } 1:(010)<100> \\
\text { Case } 2:(110)<00 \overline{1}> \\
\text { Case } 3:(111)<\overline{1} 10>\end{array}$ \\
\hline $\begin{array}{l}\text { Rake and clearance angle of the cutting } \\
\text { tool }\end{array}$ & $-25^{\circ}$ and $10^{\circ}$ \\
\hline Workpiece temperature & $\begin{array}{c}300 \mathrm{~K}, 500 \mathrm{~K}, 750 \mathrm{~K}, 850 \mathrm{~K}, 1173 \mathrm{~K} \text { and } \\
1500 \mathrm{~K}\end{array}$ \\
\hline Cutting speed & $50 \mathrm{~m} / \mathrm{s}$ \\
\hline Time step & $1 \mathrm{fs}$ \\
\hline $\begin{array}{l}\text { Potential energy function used for } \\
\text { nanometric cutting }\end{array}$ & ABOP [13] \\
\hline
\end{tabular}

\section{Results and discussions}

\subsection{Testing of the interatomic potential functions}

The accuracy of the two potential functions in reproducing the mechanical properties of silicon such as elastic constants, Bulk modulus, Shear modulus, Young's modulus (on three different orientations), anisotropy ratio and Voigt Poisson's ratio are examined first in order to make a judgement for the employability of the appropriate potential function. Table 3 presents a comparison of the aforementioned parameters obtained both by ABOP and modified Tersoff potentials against experimental values. It may be seen from Table 3 that the 
predictions made by the ABOP potential are consistent with the experiments whereas there exists a remarkable discrepancy between the experimental values and the predictions made by the modified Tersoff potential.

Table 3. Experimental properties of single crystal silicon compared with the MD simulation

\begin{tabular}{|c|c|c|c|}
\hline Mechanical properties of silicon & ABOP & $\begin{array}{l}\text { Modified } \\
\text { Tersoff }\end{array}$ & $\begin{array}{c}\text { Experiment } \\
{[27]}\end{array}$ \\
\hline $\mathrm{C}_{11}=\mathrm{C}_{22}=\mathrm{C}_{33}(\mathrm{GPa})$ & 167 & 121 & 168 \\
\hline $\mathrm{C}_{12}=\mathrm{C}_{13}=\mathrm{C}_{23}(\mathrm{GPa})$ & 65 & 86 & 65 \\
\hline $\mathrm{C}_{44}=\mathrm{C}_{55}=\mathrm{C}_{66}(\mathrm{GPa})$ & 60 & 49 & 80 \\
\hline $\begin{array}{l}\text { Anisotropy ratio (A) } \\
\frac{2 C_{44}}{C_{11}-C_{12}}\end{array}$ & 1.176 & 2.8 & 1.553 \\
\hline $\begin{array}{l}\text { Bulk modulus (B) (GPa) } \\
\qquad \frac{C_{11}+2 C_{12}}{3}\end{array}$ & 99 & 98 & 99 \\
\hline $\begin{array}{l}\text { Shear modulus (G) (GPa) } \\
\frac{C_{11}-C_{12}+C_{44}}{3}\end{array}$ & 54 & 28 & 61 \\
\hline $\begin{array}{l}\text { Young's modulus }\left(\mathrm{E}_{100}\right)(\mathrm{GPa}) \\
\qquad C_{11}-2 \frac{C_{12}}{C_{11}+C_{12}} C_{12}\end{array}$ & 130.5 & 49.5 & 132 \\
\hline $\begin{array}{l}\text { Young's modulus (E } 110)(\mathrm{GPa}) \\
4 \frac{\left(C_{11}{ }^{2}+C_{12} C_{11}-2 C_{12}{ }^{2}\right) C_{44}}{2 C_{44} C_{11}+C_{11}{ }^{2}+C_{12} C_{11}-2 C_{12}{ }^{2}}\end{array}$ & 144 & 91 & 171 \\
\hline Young's modulus $\left(\mathrm{E}_{111}\right)(\mathrm{GPa})$ & 150 & 126 & 189 \\
\hline
\end{tabular}




\begin{tabular}{|c|c|c|c|}
\hline $3 \frac{C_{44}\left(C_{11}+2 C_{12}\right)}{C_{11}+2 C_{12}+C_{44}}$ & & \\
\hline Voigt Poisson's ratio & & & \\
\hline$C_{12}-\frac{2 C_{44}+C_{12}-C_{11}}{5}$ & 0.26 & 0.33 & 0.22 \\
\hline $2\left(C_{12}+C_{44}-2 \frac{2 C_{44}+C_{12}-C_{11}}{5}\right)$ & & & \\
\hline
\end{tabular}

We evaluated the employability of the two potentials further by carrying out nanoscale tensile and shear tests on silicon and the results from these tests are being provided as supplementary information to our cutting simulation results. The strain controlled simulation tests were prescribed a strain rate of $\left(5 \times 10^{-7}\right) \mathrm{s}^{-1}$ along the $<100>$ axis of silicon nanowire. The size of the rectangular silicon nanowire employed during the tensile test was $32.5 \mathrm{~nm} \times 8.1 \mathrm{~nm} \times 8.1 \mathrm{~nm}$, while the one used for the shear test was $16.3 \mathrm{~nm} \times 16.3 \mathrm{~nm} \times 8.1 \mathrm{~nm}$. Periodic boundary condition was applied along the direction of applied strain ( $x$-axis) whereas shrink-wrapped boundaries were applied in the lateral dimensions. The typical tensile and shear stress-strain response of the [100]-oriented silicon nanowire at room temperature is shown in Fig. 2. The values of Young's modulus $(E)$ and shear modulus $(G)$ were also obtained by fitting the stress-strain curves to straight lines in the strain range of 0 to $5 \%$. The Young's modulus calculated by the ABOP at room temperature is around $131 \mathrm{GPa}$, which is close to the Young's modulus of $\mathrm{Si}<001>$ nanowires obtained from first-principle density functional theory ( 122 GPa) [28]. The stress curve follows the non-linear elastic behaviour and the specimen deforms until abrupt fracture occurs. As shown in Fig. 2, while using the ABOP, the stress suddenly drops to zero immediately after the fracture and can be regarded as a typical cleavage fracture on a transverse $(010)$ plane. The fracture surface in the tensile test specimen was found to be perpendicular to the pulling direction, which is the $x$-axis. Thus, the mode of failure of silicon nanowire shown by the ABOP potential was a typical brittle 
fracture behaviour as opposed to ductile deformation shown by the modified variant of the Tersoff. Also, as evident in Fig. 2b, the modified Tersoff showed that the shear failure takes place on a (111) sliding plane.

From what has been discussed above, one may deduce that ABOP is robust in describing the mechanical properties of silicon over the modified variant of Tersoff. Therefore, we adopt the ABOP potential in the present study which is focussed on reporting mechanical properties of silicon and whenever needed a comparison is made between the results obtained by both the potentials.

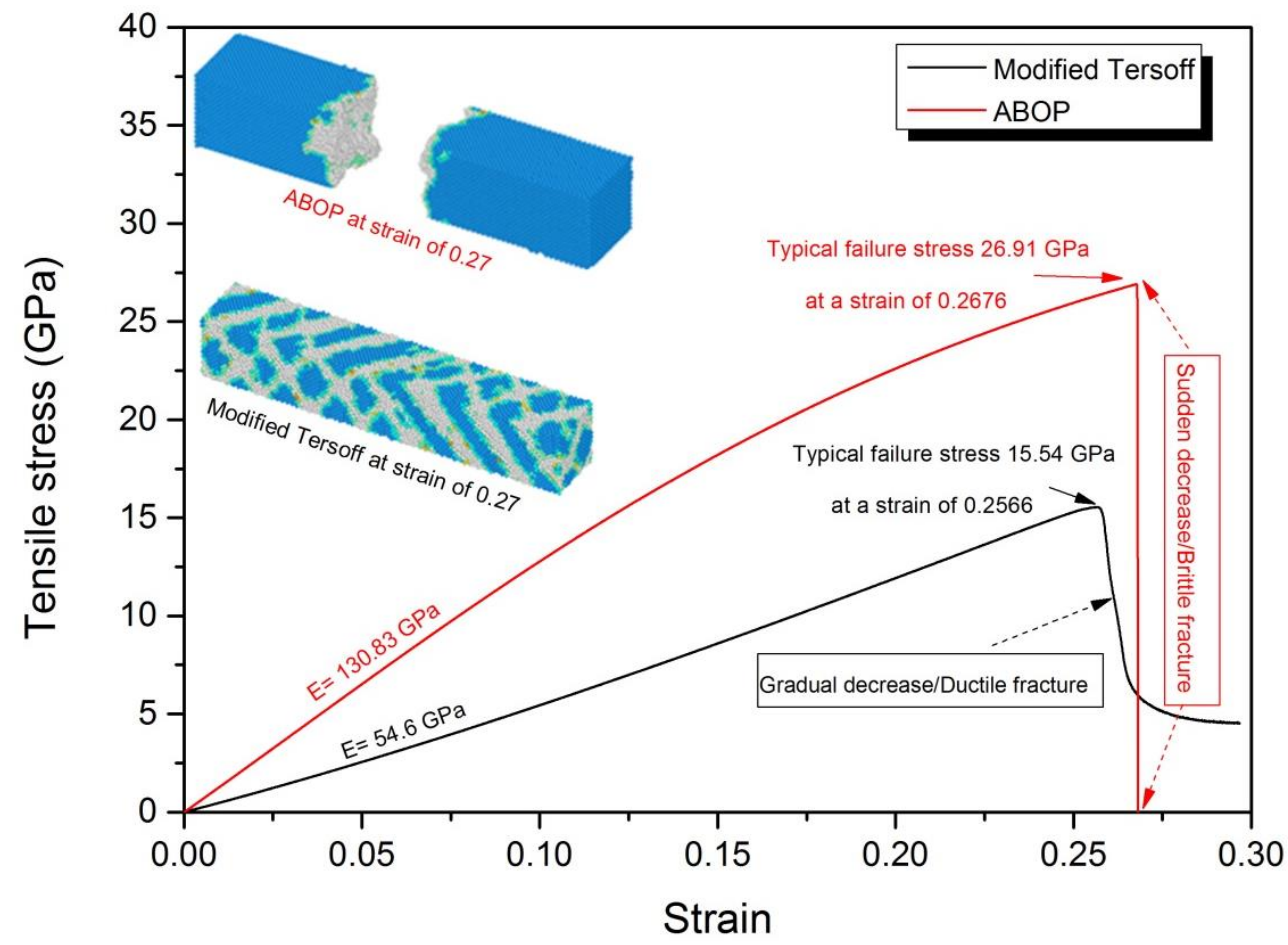

(a) 


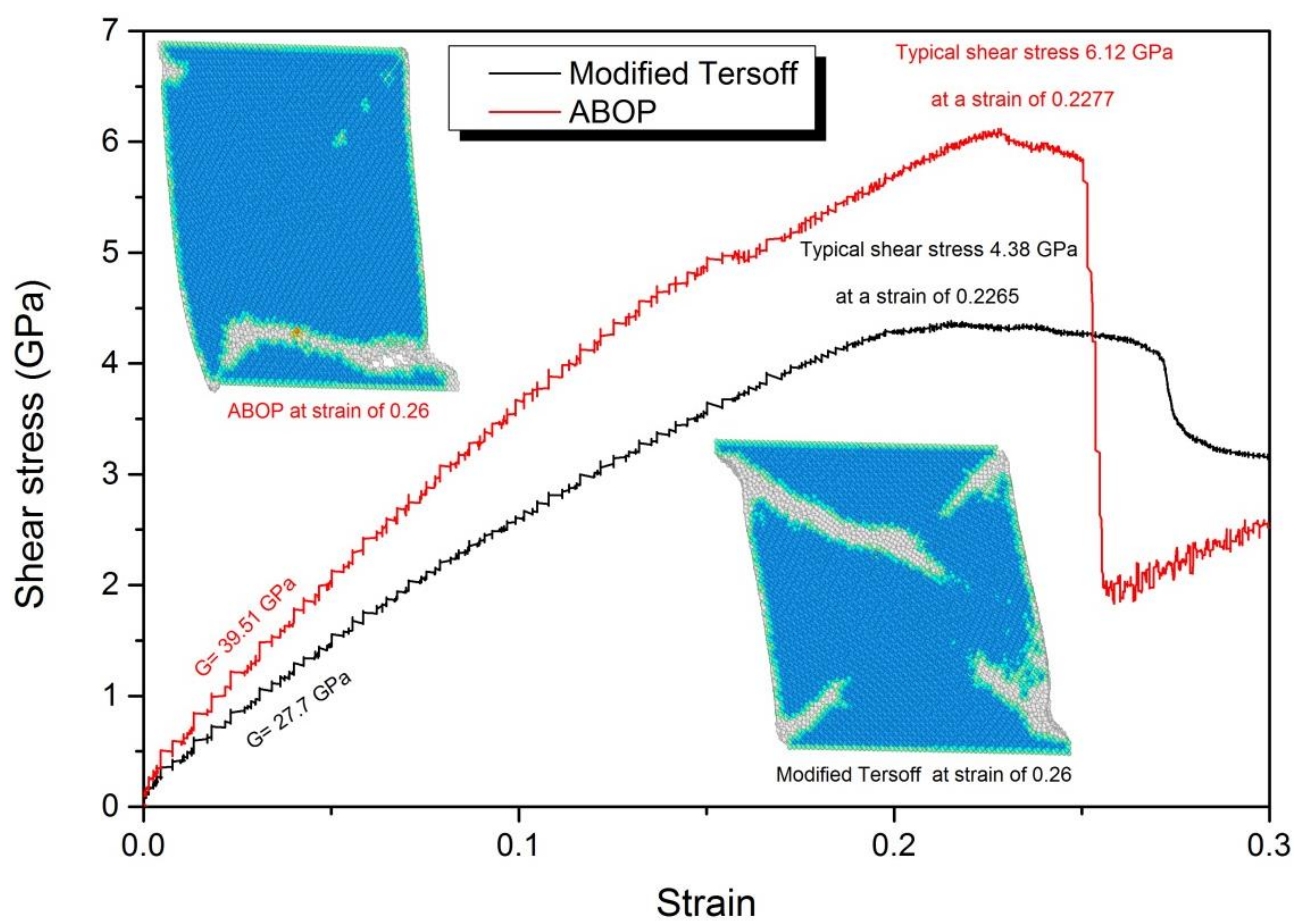

(b)

Fig. 2. (a) Tensile stress-strain curve and (b) shear stress-strain curve of the [100]-oriented single crystal silicon at $300 \mathrm{~K}$ obtained by modified Tersoff and ABOP potential energy functions

\subsection{Cutting forces and other indicators}

The cutting behaviour changes dynamically i.e. wear, fracture, elastic-plastic transition, displacement of the material, heat generation, dislocation slip etc. leading to the variation of the force acting on the tool along the length of cut. Also, experiments [29] and simulations [30] have shown that silicon is an intrinsically-anisotropic material even during cutting at room temperature. Hence, calculation of machining force was necessary and to do this, the total force exerted by the carbon atoms of the cutting tool on the silicon workpiece was calculated.

The magnitude of the average tangential cutting forces $\left(F_{c}\right.$ in $\left.\mathrm{nN}\right)$, thrust forces $\left(F_{t}\right.$ in $\left.\mathrm{nN}\right)$, resultant forces $\left(R=\left(\operatorname{sqrt}\left(F c^{2}+F t^{2}\right)\right)\right.$ in $\left.\mathrm{nN}\right)$, force ratio $\left(F_{c} / F_{t}\right)$ and specific cutting energy ( $u$ in GPa) for all the simulated temperatures and crystal planes were calculated and are 
provided as appendix (see Table 1A in Appendix A). As expected, the force data reveals that the magnitude of tangential, thrust and resultant forces decreases with an increase in the workpiece temperature on different crystallographic planes. It is because of the fact that an increase in the workpiece temperature increases the amplitude of atomic vibration in the workpiece atoms, which is regarded as an increase in the number of phonons. This phenomenon results in generating atomic displacements. The atomic displacements within the workpiece causes an increase in the interatomic distances and a decrease in the restoring forces due to thermal expansion, leading to lowering of the energy required to break the atomic bonds. As a consequence, thermal softening occurring until a certain critical temperature reduces the cutting force required to deform the silicon substrate at high temperatures.

Fig. 3 presents a comparison of the cutting anisotropy measured in terms of specific cutting energy at different cutting temperatures. In general, lower specific cutting energy indicates better machinability. Fig. 3 shows that low temperature machining leads to large specific cutting energy which is in accord with the cutting force data. A common observation evident from Fig. 3 is that the anisotropy persists even at high temperatures. It may be seen that the (111) orientation requires least specific cutting energy whereas the highest values appears on the (110) orientation. It is documented that the slip in diamond cubic lattice is analogous to FCC crystals and occurs preferentially on the (111) slip planes, meaning thereby that the (111) orientation should result in low specific cutting energy. Moreover, it has been experimentally demonstrated that the (111) silicon surface provides a finer quality of machined surface roughness [1] and requires low specific cutting energy. Overall, it can be inferred that the $(111)<\overline{1} 10>$ and $(010)<100>$ crystal setups are the easy cutting combinations of orientation and directions for cutting silicon which is in accord with the published experimental results [29]. 


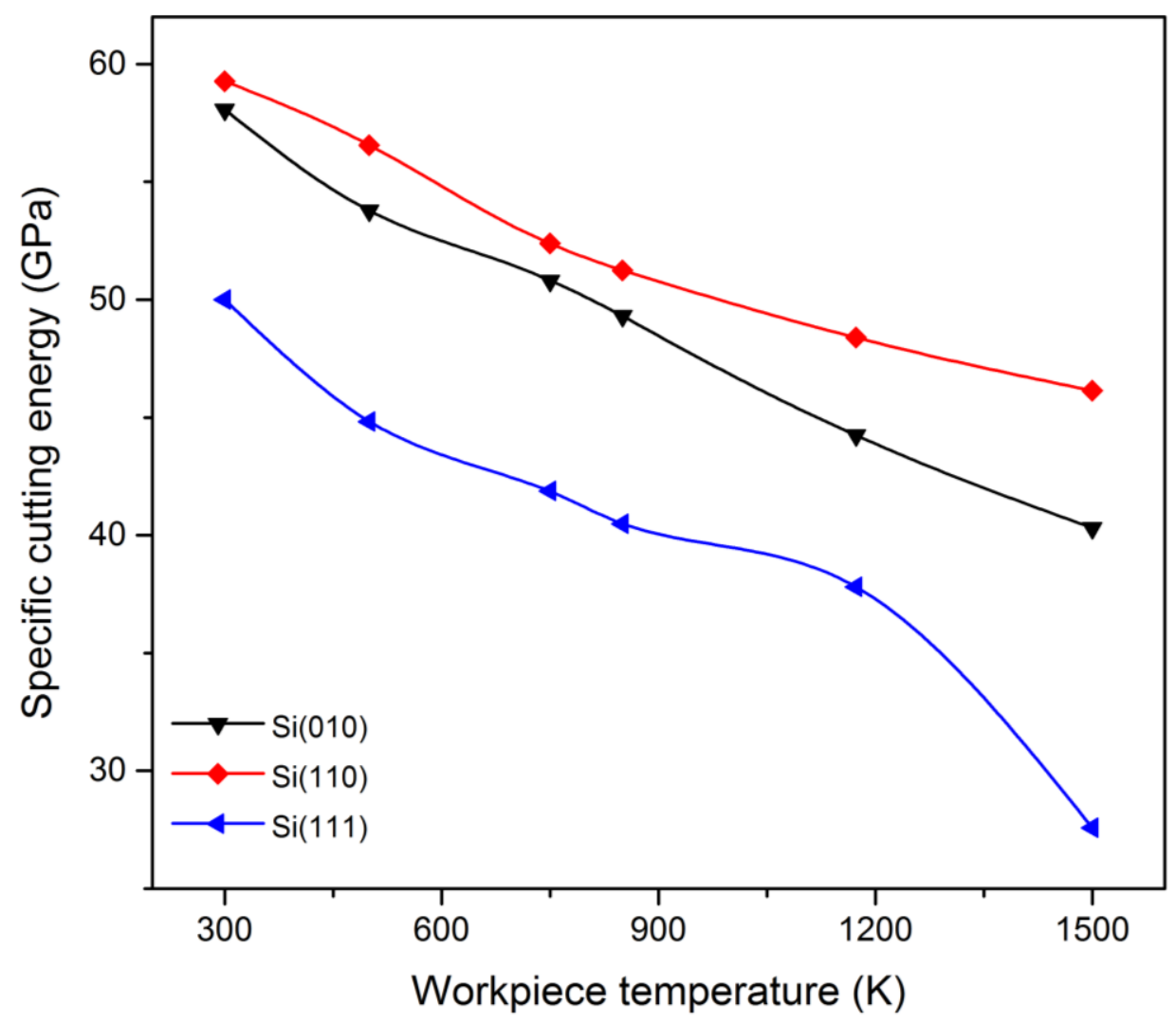

Fig. 4. Specific cutting energy as a function of temperature and crystal orientation

The percentage reduction in the tangential force, thrust force, resultant force and specific cutting energy during elevated temperature cutting with respect to cutting at $300 \mathrm{~K}$ on different crystallographic orientations obtained by ABOP is highlighted in Table 4. It was observed that the maximum reduction occurs on the (111) and (010) crystal planes, which is up to $25 \%$. Furthermore, the anisotropy (cutting forces and specific cutting energy) was found to increase with the rise of temperature i.e. it increases from $\sim 16 \%$ at $300 \mathrm{~K}$ to $\sim 20 \%$ at $1173 \mathrm{~K}$ and to $\sim 40 \%$ at $1500 \mathrm{~K}$, respectively.

Table 4. Percentage reduction in tangential, thrust, resultant forces and specific cutting energy of silicon at high temperatures relative to room temperature

\begin{tabular}{|c|c|c|}
\hline $\begin{array}{c}\text { Crystal } \\
\text { orientation }\end{array}$ & $\begin{array}{c}\text { \% reduction in } \\
\text { machining }\end{array}$ & $\begin{array}{c}\% \text { reduction in } \\
\text { machining }\end{array}$ \\
\hline
\end{tabular}




\begin{tabular}{|c|c|c|}
\hline & $\begin{array}{c}\text { energy at 850 K } \\
\text { compared to } 300 \\
\mathrm{~K}\end{array}$ & $\begin{array}{c}\text { energy at 1173 } \\
\text { K compared to } \\
300 \mathrm{~K}\end{array}$ \\
\hline$(010)$ & Up to $15 \%$ & Up to $24 \%$ \\
\hline$(110)$ & Up to $14 \%$ & Up to $19 \%$ \\
\hline$(111)$ & Up to $19 \%$ & Up to $25 \%$ \\
\hline
\end{tabular}

The ratio of the tangential cutting force to the thrust force provides the force ratio, which is also called as coefficient of kinetic friction. Fig. 4 presents variation in the average force ratio during nanometric cutting of silicon obtained from ABOP in the range of $300 \mathrm{~K}-1500 \mathrm{~K}$ for each crystallographic orientation. The error bars in Fig. 4 signify the magnitude of standard deviation and fluctuations in the average force ratio. The force ratio varies from 0.58 to 1.03 on different crystal planes and temperatures. It may be noted that the force ratio is maximum on the (111) orientation while it is minimum on the (110) orientation. A notable observation is that the force ratio remains unchanged up to $1173 \mathrm{~K}$ on all the three crystallographic planes and a sudden and abrupt change occurs beyond $1173 \mathrm{~K}$.

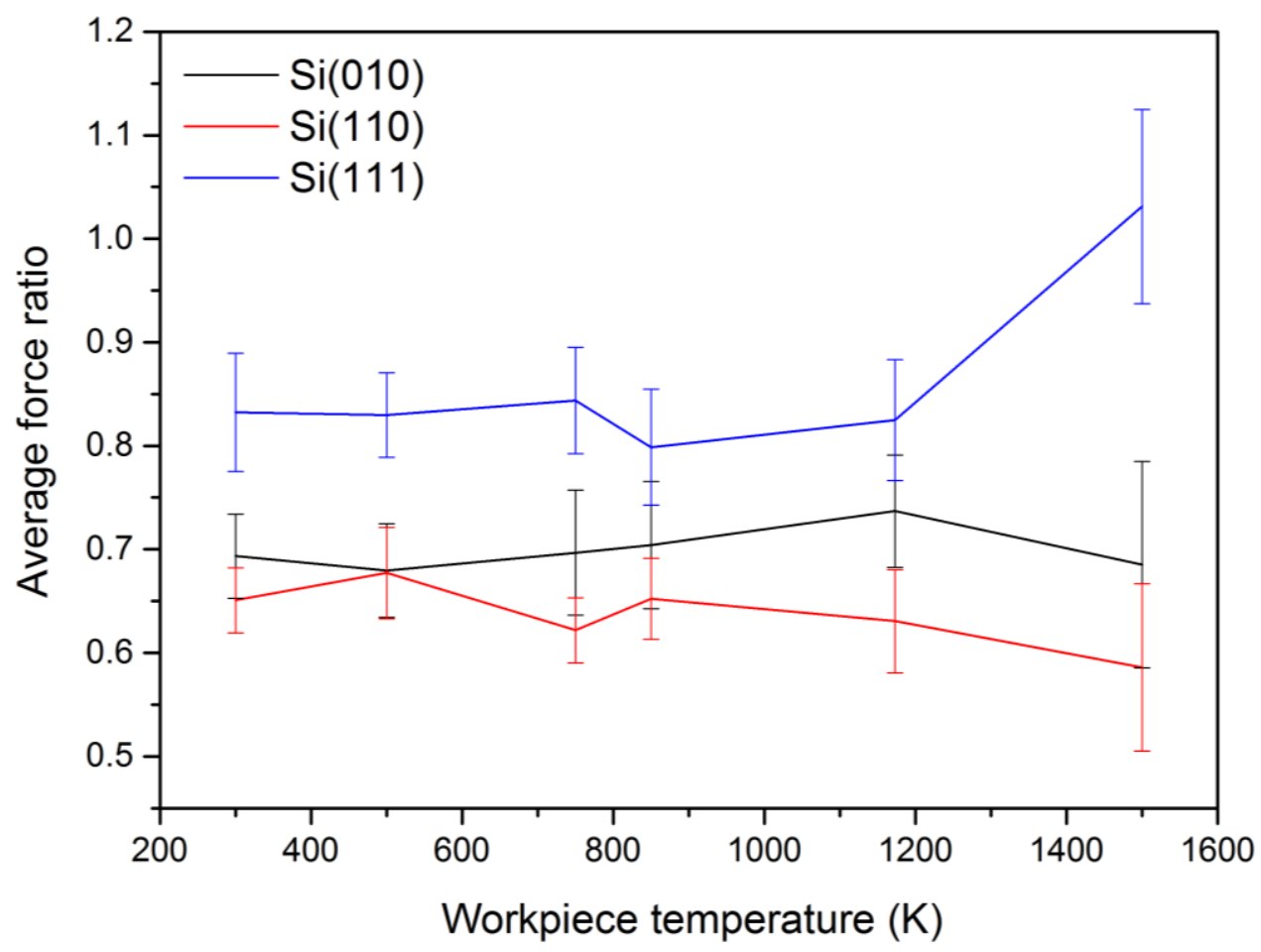


Fig. 4. Variation in the average force ratio while cutting silicon on different crystallographic planes at various temperatures

\subsection{Machining temperature}

During nanometric cutting, heat is generated due to reconfiguration of the bonding arrangements in the cutting zone and due to the friction between the cutting tool and the workpiece. Fig. 5 illustrates the temperature evolution in the Newtonian atoms of the workpiece while cutting single crystal silicon on the (110) crystal surface at different temperatures. It should be noted here that the same trend was observed for the other two crystallographic orientations and hence those are not repeated here for brevity.

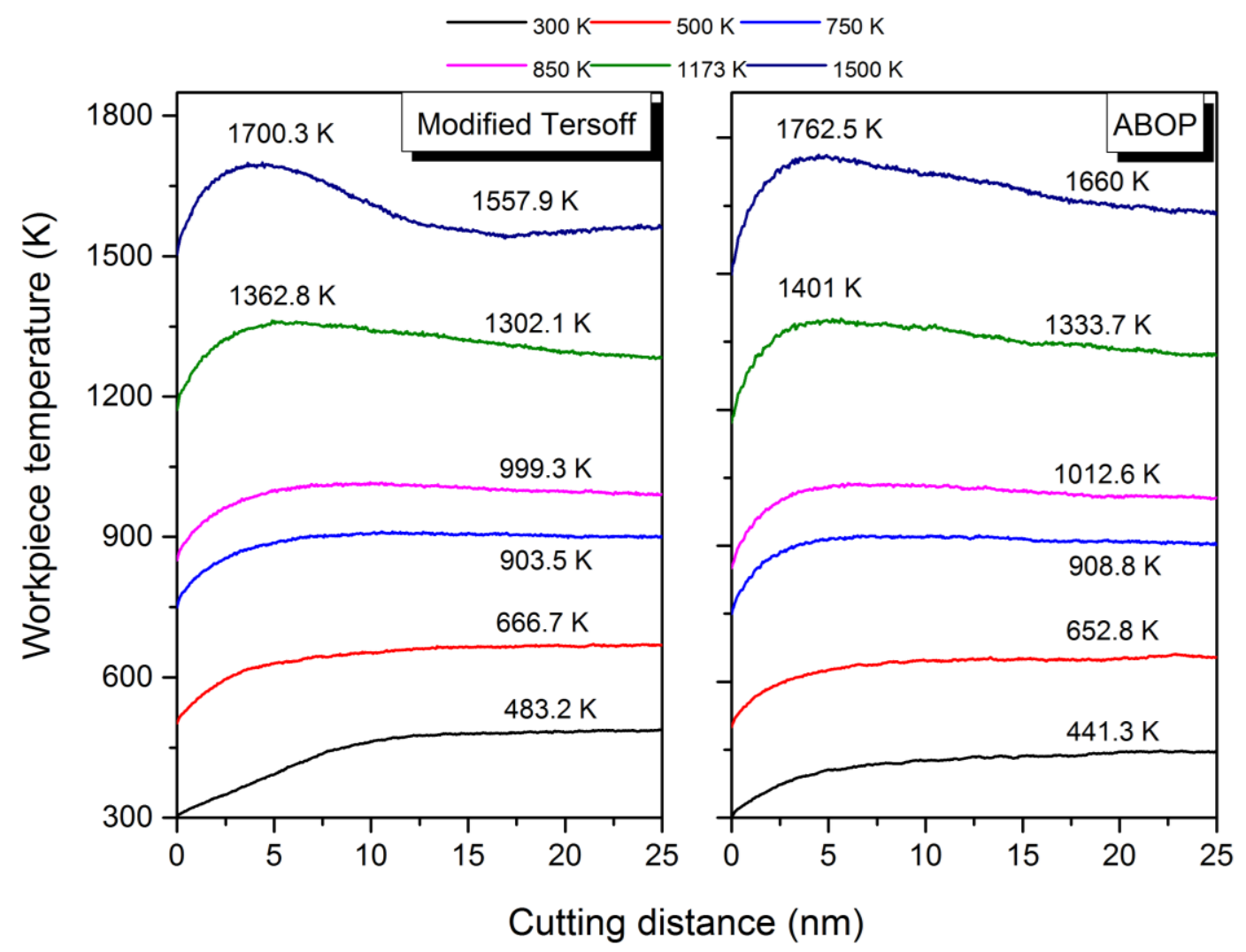

Fig. 5. Evolution of the average temperature of Newtonian atoms of workpiece while cutting on the (110) crystal plane 


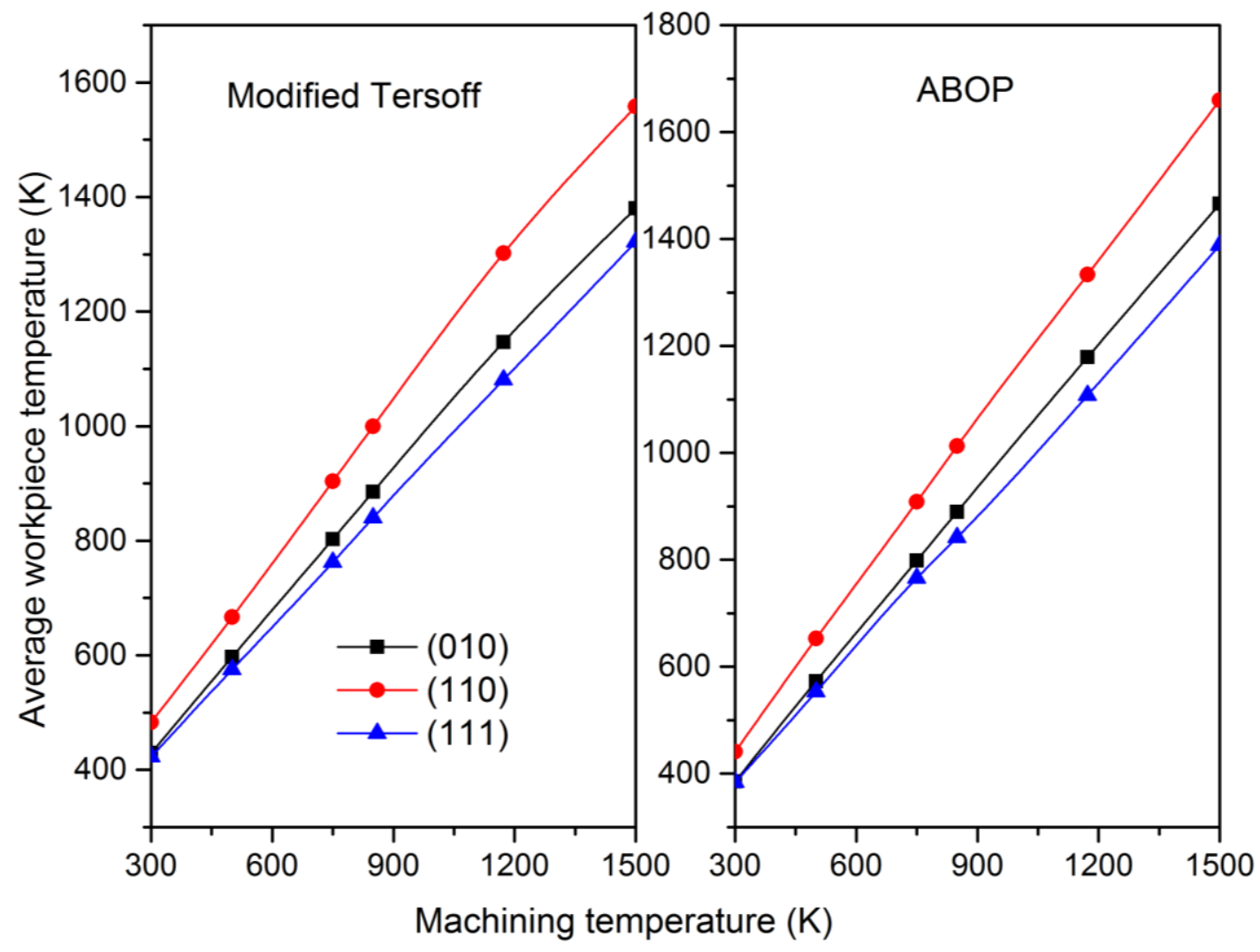

Fig. 6. Anisotropy in the cutting temperature in the Newtonian atoms of the workpiece obtained from the two potentials

The evolution of peak cutting temperature in the silicon workpiece on the three principal orientations for both the potential functions is shown in Fig. 6. It may be seen from Fig. 6, that hot machining on the (111) crystal plane showed least temperature in comparison to the other two orientations, which is in agreement with the results obtained for cutting forces and specific cutting energy in different scenarios. It may also be seen that at high temperatures, ABOP predicts higher average temperatures of the workpiece than the modified Tersoff, coming from the overestimated melting temperature of silicon by the ABOP.

The anisotropy in the cutting temperature was observed to increase with the rise of machining temperature i.e. it increases from $\sim 12 \%$ at $300 \mathrm{~K}$ to $\sim 17 \%$ at $1173 \mathrm{~K}$ and $1500 \mathrm{~K}$, respectively. The trend is similar to what was seen in the anisotropy of cutting force and specific cutting energy required to cut silicon on three orientations. 


\section{4. von Mises shear strain}

In order to quantitatively and qualitatively assert the degree of deformation in the shear zone, an algorithm proposed by Shimizu et al. [31] was used in this study. Two atomic configurations (during cutting and before cutting) were compared and then the atomic local shear strain (von Mises strain) was calculated for the configuration of atoms. The local Lagrangian strain matrix was computed by using a local deformation matrix $J_{i}$ and Equation 2, so as to calculate the von Mises shear strain for each atom $i$. The von Mises shear strain $\eta_{i}^{\text {Mises }}$, which has been documented as an excellent measure of the local inelastic deformation, was calculated through Equation 3 [32] where $\eta_{\mathrm{ij}}$ are six atomic strain tensors.

$$
\begin{aligned}
& \eta_{i}=\frac{1}{2}\left(J_{i} J_{i}^{T}-I\right) \\
& \eta_{i}^{\text {Mises }}=\sqrt{\eta_{y z}^{2}+\eta_{x z}^{2}+\eta_{x y}^{2}+\frac{\left(\eta_{y y}^{2}-\eta_{z z}^{2}\right)+\left(\eta_{x x}^{2}-\eta_{z z}^{2}\right)+\left(\eta_{x x}^{2}-\eta_{y y}^{2}\right)}{6}}
\end{aligned}
$$

Fig. 7 illustrates the atomic shear strain distribution in the workpiece for the representative temperatures of $300 \mathrm{~K}$ and $850 \mathrm{~K}$ and crystal planes of (010), (110) and (111). In the simulation snapshots shown in Fig. 7, bright regions (white and yellowish regions) can be seen to exhibit higher strain. It is evident that shear strain localizes in the primary shear zone and underneath the flank face of cutting tool where the material undergoes intense deformation. Machining experiments and simulations have helped in identifying that chip formation is driven by the shearing process primarily in the primary shear zone leading to release of excessive heat. Due to the ease of deformation of the workpiece at high temperatures, a narrower primary shear zone can be observed during hot machining. Smaller primary shear zone implies that shear occurs in a more confined area leading to lowering of 
the cutting forces. As demonstrated in Fig. $7 \mathrm{~b}$ and $7 \mathrm{~d}$, a wider primary shear zone is observed whilst hot nanometric cutting was performed on the (110) crystal surface, indicating that higher shear forces are associated with the chip formation on this plane. Thus, the (110) plane can be considered as the difficult to cut orientation while the (111) orientation offers easy machinability once again confirming the same findings as observed in the experiments [33].

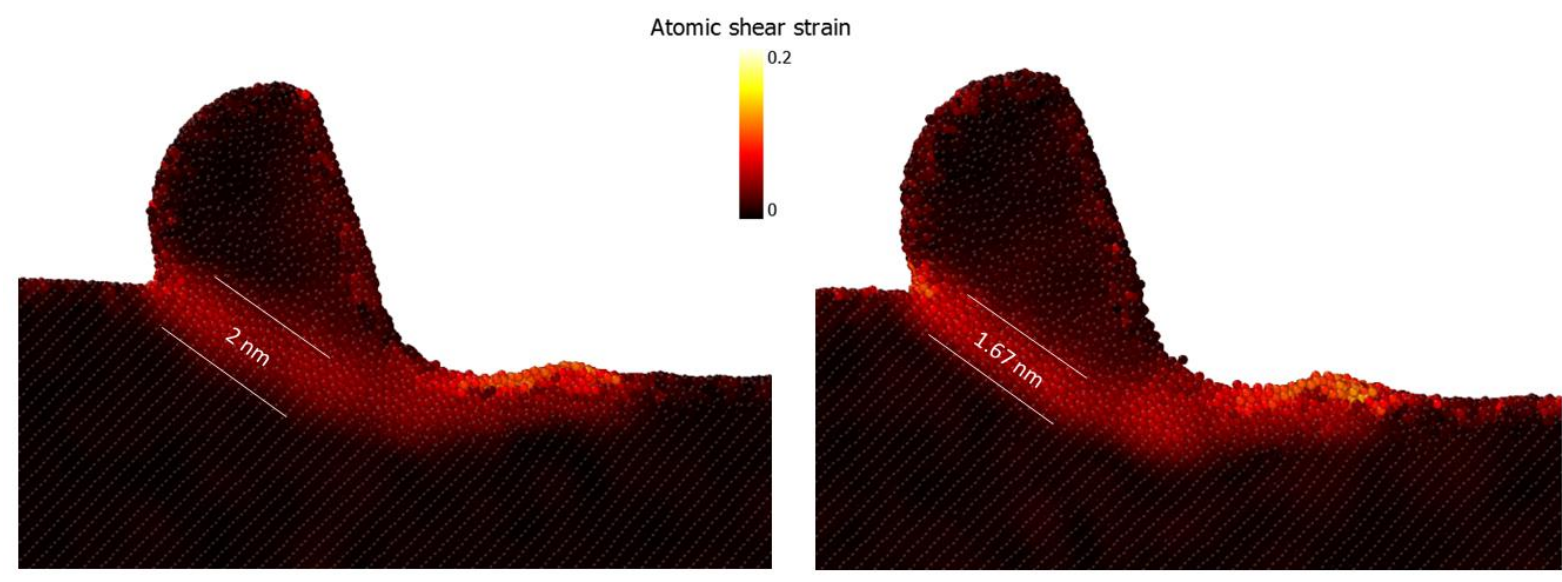

(a) (010) at $300 \mathrm{~K}$

(b) (010) at $850 \mathrm{~K}$
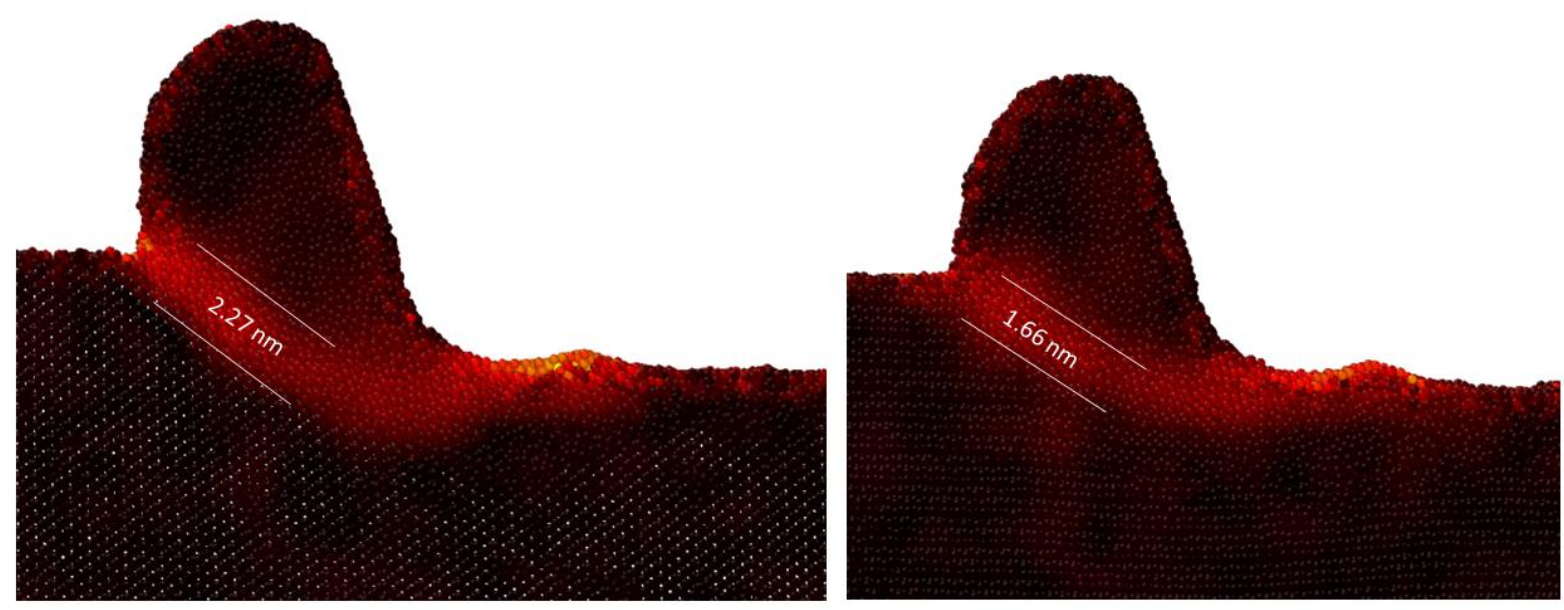

(c) (110) at $850 \mathrm{~K}$

(d) (111) at $850 \mathrm{~K}$

Fig. 7. The local von Mises strain distribution and cut chip thickness after $20 \mathrm{~nm}$ cutting distance. A wider primary shear zone can be seen on the (110) orientation.

\subsection{Machining stress and temperature in the cutting zone}

The von Mises stress is a very commonly used yield criterion to predict yielding of a material 
and is based on the assumption that it is the maximum deviatoric strain energy that brings yielding in the material. In addition to von Mises stress measure, there are other material dependent stress measures that are proposed to predict yielding such as Principal stress measure, Tresca stress measure and these were also evaluated and are shown in Table 1B in Appendix B. It summarizes the magnitude of all the stress measures and temperatures in the cutting zone for all the simulated cases. An elemental atomic volume $\left(1 \times 1.5 \times 3 \mathrm{~nm}^{3} \sim 210\right.$ atoms) was considered in the cutting region for the sake of calculating the atomic stress tensor based on the procedure defined in LAMMPS $^{1}$. Fig. 8 compares von Mises stress obtained from the ABOP potential function at different machining temperatures and crystal orientations while cutting silicon. It has been experimentally reported that at room temperature, the onset of plastic yielding in single crystal silicon occurs in the pressure range of 9 to $16 \mathrm{GPa}$ [34]. Although pressure relates to hydrostatic stress as opposed to deviatoric stress (which is more realistic in a nanometric cutting scenario) but von Mises stress could still be considered as a valid comparison against pressure assuming that a scalar magnitude of von Mises stress at a point is hydrostatic in nature. It may be seen that the ABOP potential predicts the critical von Mises stress of silicon during cutting at $300 \mathrm{~K}$ in the range of $\sim 12.9$ $\mathrm{GPa}$ to $14.6 \mathrm{GPa}$ which is consistent with the previously reported magnitude of $\sim 14 \mathrm{GPa}$ [35]. The dummy trials performed using the modified Tersoff potential function predicted the von Mises stress in the range of $\sim 7.1 \mathrm{GPa}$ to $8.7 \mathrm{GPa}$, signifying that this potential underestimates the yielding in single crystal silicon.

A noteworthy finding is that the maximum reduction in the von Mises stress at $1500 \mathrm{~K}$ with respect to the room temperature machining takes place on the (111) plane, which is up to $37 \%$, followed by the (010) crystal plane, consistent with the already witnessed behaviour in specific cutting energy. It may also be seen that the von Mises stress in the temperature range

\footnotetext{
${ }^{1}$ http://lammps.sandia.gov/doc/compute_stress_atom.html
} 
of $300 \mathrm{~K}$ to $1173 \mathrm{~K}$ varies only slightly while cutting silicon on the (110) crystal plane. Such behaviour was observed for the (010) surface in the range of $750 \mathrm{~K}$ to $1173 \mathrm{~K}$. It is also interesting to note that the largest value of the von Mises stress causing yielding on the (111) crystal plane appears at low temperatures, i.e. $300 \mathrm{~K}$ and $500 \mathrm{~K}$. Another key finding is that the anisotropy in von Mises stress was found to increase from $\sim 12 \%$ at $300 \mathrm{~K}$ to up to $\sim 20 \%$ at high temperatures of $1173 \mathrm{~K}$ and $1500 \mathrm{~K}$ obtained from the $\mathrm{ABOP}$ function.

In general, the maximum and minimum heat in the cutting zone is generated on the $(010)$ and (111) crystal planes, respectively, which is analogous to the already observed behaviour in workpiece temperature. Moreover, the anisotropy in the temperature at the onset of plastic yielding is found to increase from $\sim 7 \%$ at $300 \mathrm{~K}$ to $20 \%$ at $1500 \mathrm{~K}$. Similar to the observed trend in the anisotropy of cutting forces, specific cutting energies, workpiece and tool temperature, the anisotropy in the peak temperature in the cutting zone and temperature at the onset of plastic yielding is witnessed to increase with the increase of machining temperature.

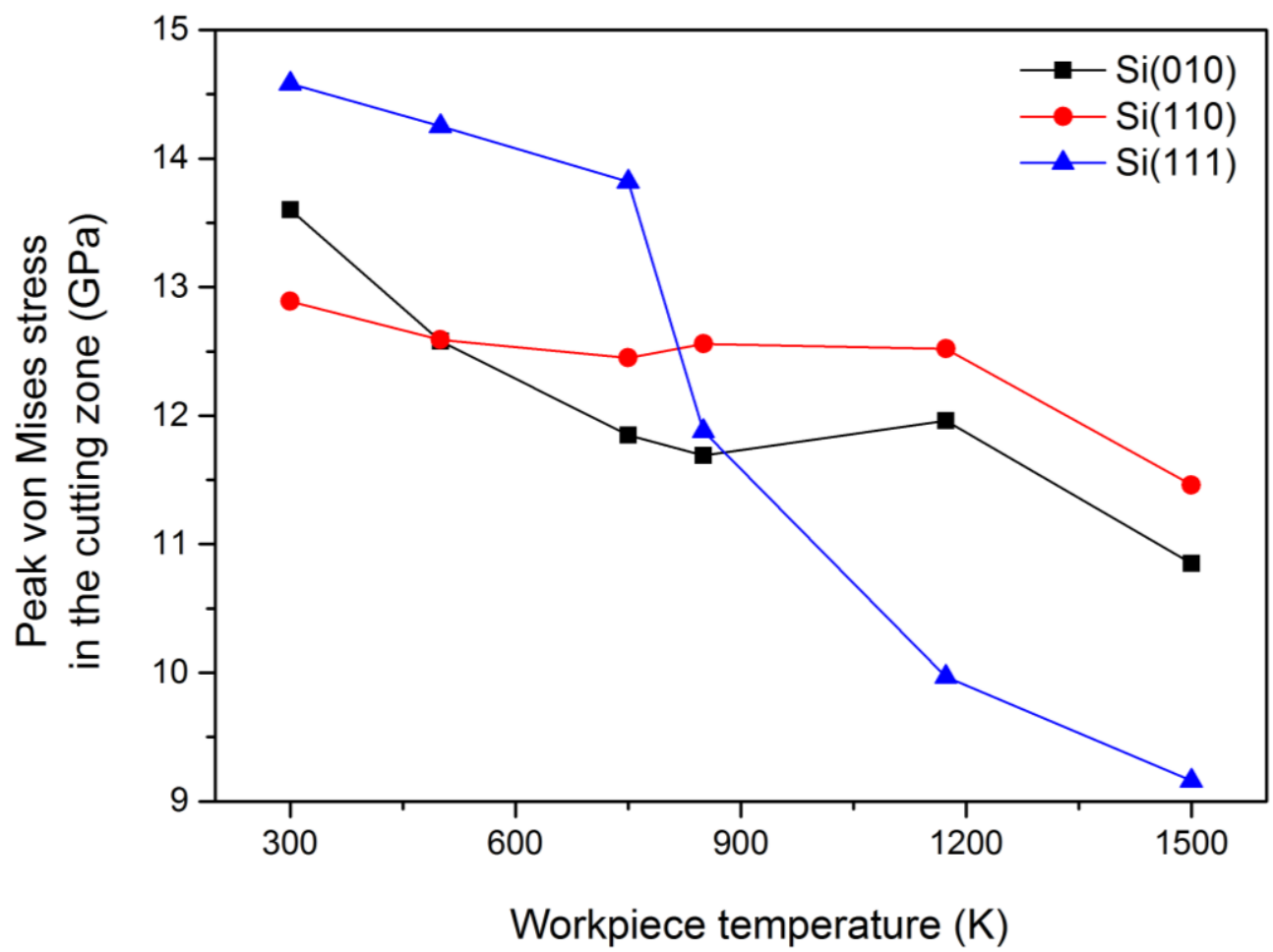

Fig. 8. von Mises stress anisotropy in the cutting zone while machining silicon at different 
cutting temperatures

In order to gain further insights on the behaviour of the substrate, evolution of average local temperature and von Mises stress in the cutting zone while cutting silicon on the (010) are plotted in Fig. 9. The trend was observed to be the same for the other crystal planes and hence not repeated. It was observed that the peak temperature in the cutting zone follows peak stress at low temperatures, i.e. $300 \mathrm{~K}$, whereas at high temperatures, viz. $1173 \mathrm{~K}$, the peak temperature lags the peak stress. It can be inferred from Fig. 9 that the peak temperature and peak stress required to cause yielding in the cutting zone do not occur concurrently. This difference exist because the energy required to cause the breaking of bonds is directly dependent on the cutting temperature which means, higher the temperature, lower is the stress required to yield the material. This is why yielding at $595 \mathrm{~K}$ takes place at $13.6 \mathrm{GPa}$ during cutting at $300 \mathrm{~K}$ whereas yielding at $1152 \mathrm{~K}$ takes place at $11.96 \mathrm{GPa}$ at elevated temperature cutting. This confirms the initial hypothesis quantitatively that hot machining reduces the cutting resistance of silicon. 


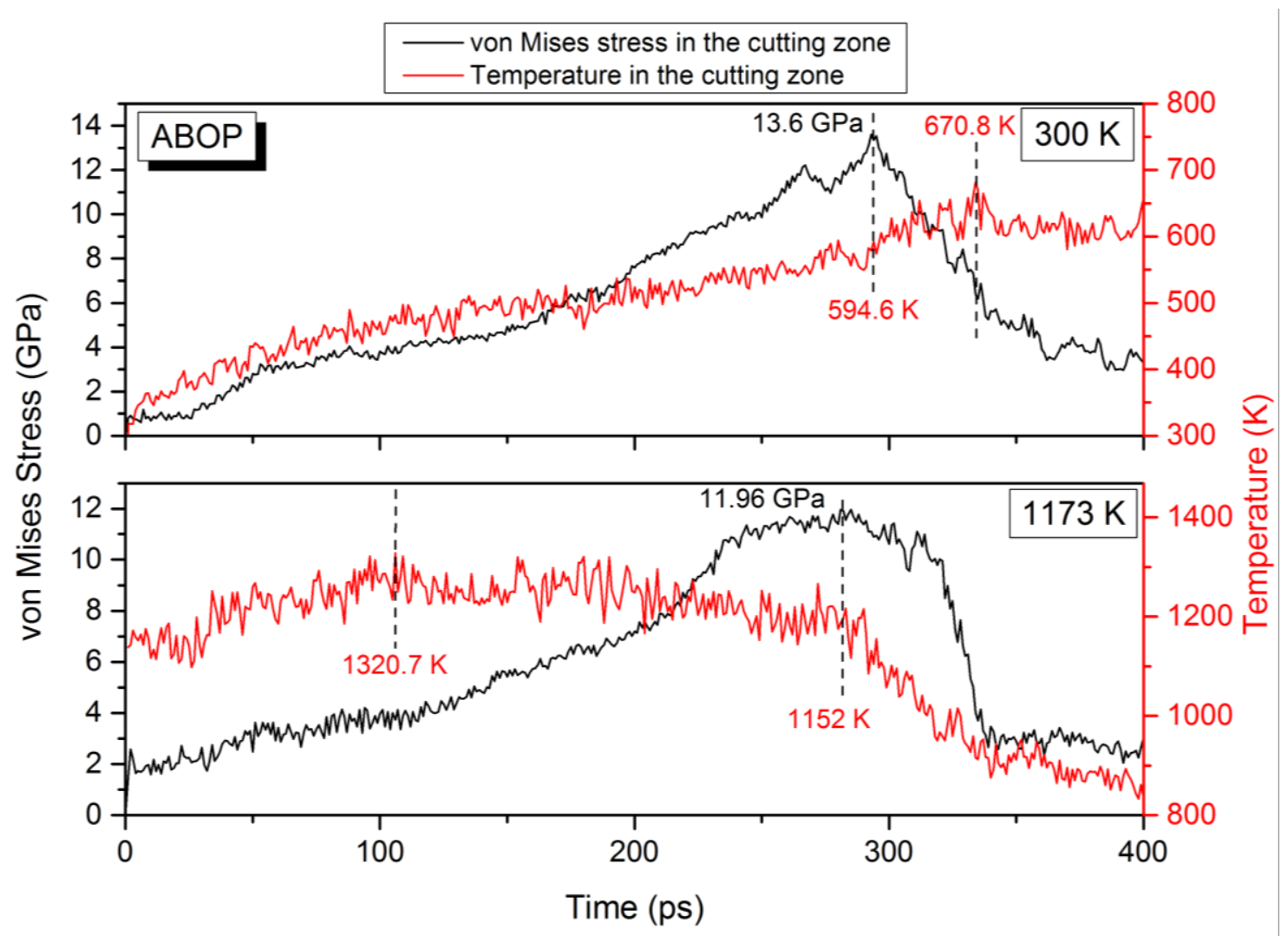

Fig. 9. Evolution of the temperature and von Mises stress in the cutting zone recorded on the same plot while cutting on the (010) plane

\subsection{Machining stress and temperature on the cutting edge of the tool}

Following discussions on machining of silicon, an attempt was made to examine the state of the diamond tool post-machining. It has been reported that under confined pressure $(3.5 \mathrm{GPa}$ to $5 \mathrm{GPa})$ and at high temperatures $(>1200 \mathrm{~K}-1300 \mathrm{~K})$ diamond may exhibit ductile flow, which is meditated by dislocation glide and twinning [36-37]. During nanometric cutting, cutting edge of the diamond tool experiences high stress and consistent exposure to high temperature conditions that could promote its ductile deformation. The observations witnessed in the above description proves that high machining temperature enhances ductile response of silicon which leads us to anticipate lower tool wear during the high temperature cutting process. It must however be recalled that high heat content is closely associated with 
the wear of diamond i.e. hot environment can bring about accelerated wear of carbon atoms via diffusion, attrition, adhesion and so on. It was therefore felt necessary to examine this hypothesis during the current investigation. Fig. 10 shows the anisotropy in the peak average von Mises stress observed on the cutting edge of the diamond tool during nanometric cutting of single crystal silicon at different temperatures. Table 1C in Appendix $\mathrm{C}$ summarizes the average magnitude of von Mises stress measure, Tresca stress measure and temperature on the cutting edge in all the simulated test cases. Fig. 10 suggests that the cutting tool experiences least stress and temperature on the (111) orientation compared to others, which makes it an easy cutting plane as has been verified from the experiments [33]. The general pattern is that the magnitude of von Mises stress and Tresca stress on the cutting edge of the tool decreases with an increase in the machining temperature for the different crystallographic planes. It was seen that the von Mises stress and Tresca stress acting on the cutting edge of the tool at low and high temperatures were in the range of 18 to $26 \mathrm{GPa}$ and 10 to $15 \mathrm{GPa}$, respectively. First-principle calculation suggest that the minimum stress needed to cause structural instability in the diamond structure is around $95 \mathrm{GPa}$ that brings a direct diamond to graphite transformation [38]. Apparently, the assessment of the state of the stress on the cutting edge of the tool during cutting in vacuum is not supportive of a direct diamond-graphite transformation.

A notable observation was that even when the nanometric cutting was simulated at $1500 \mathrm{~K}$, the peak average temperature on the cutting edge remains as low as $\sim 413 \mathrm{~K}$, suggesting that plastic deformation of diamond cutting tool is also unlikely. The question then arises as to what happens to diamond during nanometric cutting of silicon. Some investigations by the authors in this regard were made [35] yet, the post-machining phase of diamond was not found owing primarily to the unavailability of a robust potential function to predict all the phases of carbon. This is another interesting area of further research which the authors are 
willing to pursue further in the follow on work.

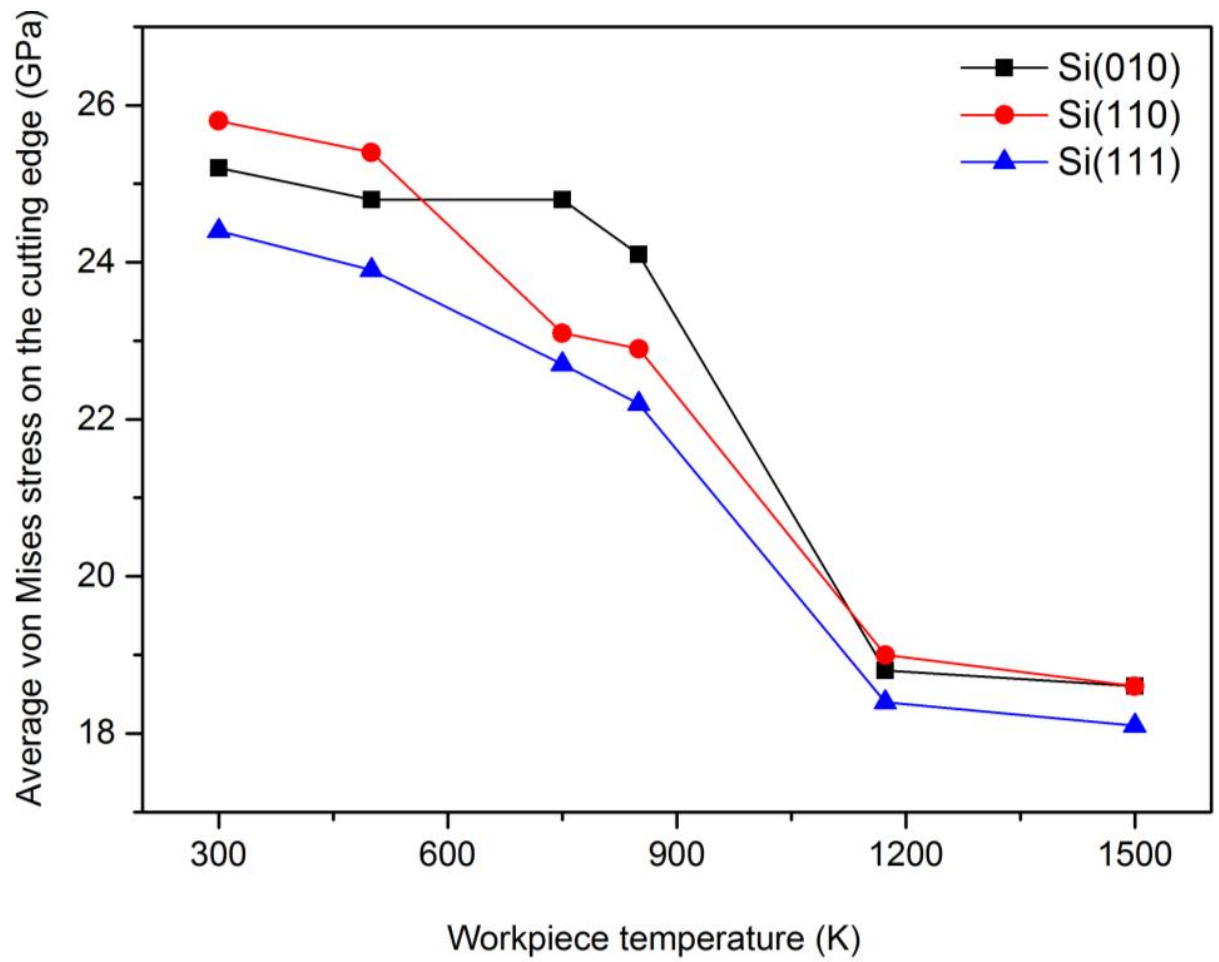

Fig. 10. Anisotropy in the von Mises stress measured on the cutting edge of the diamond tool while machining different orientations of silicon at different cutting temperatures

\section{Conclusions}

This paper employs MD simulation to explore the cutting anisotropy of single crystal silicon on the different crystallographic planes at elevated temperatures. Complimentary calculations of mechanical properties and simulation trials of nano-tensile and shear tests lend further credence to the reported findings. The main conclusions based on the aforementioned discussions could be as follows:

1. The anisotropy in the cutting forces, specific cutting energies, yielding stresses and temperatures was observed to increase with the increase of machining temperature. The maximum reduction in forces, specific cutting energy and yielding stresses with respect to the increase of machining temperature occurred on the (111) and (010) crystal planes. 
Accordingly, the maximum and minimum heat generated during the hot nanometric machining was observed on the (010) and (111) orientations.

2. The force ratio was observed to be maximum on the (111) crystal orientation and was minimum on the (110) crystal orientation. A striking observation was that the force ratio remained virtually constant up to $1173 \mathrm{~K}$ on all the three crystal orientations.

3. Narrower shear zones were observed while machining on the (111) crystal plane or at higher machining temperatures. Consequently, irrespective of the machining temperature, (111) orientation is suggested to be superior for machining silicon over other orientations which is in accord with the experiments.

4. The stress state and the temperature on the cutting edge of the diamond cutting tool during cutting in vacuum suggests that a direct diamond to graphitic transformation or the plastic deformation of the diamond cutting tool is less likely.

\section{Acknowledgment}

SZC acknowledges the use of the EPSRC (EP/K000586/1) funded ARCHIE-WeSt High Performance Computer at the University of Strathclyde while SG acknowledges the partial support of the European COST Action CA15102 of the Horizon 2020 program in undertaking this work. XL acknowledges the partial support of the EPSRC (EP/K018345/1) and Royal Society-NSFC international exchange programme (IE141422) for this study.

\section{References}

[1] S. Goel, X. Luo, A. Agrawal, R. L. Reuben, Diamond machining of silicon: A review of advances in molecular dynamics simulation, International Journal of Machine Tools \& Manufacture 88 (2015) 131-164

[2] X. Luo, S. Goel, R. L. Reuben, A quantitative assessment of nanometric machinability of 
major polytypes of single crystal silicon carbide. Journal of the European Ceramic Society 32 (2012) 3423-3434

[3] R. Komanduri, L. M. Raff, A review on the molecular dynamics simulation of machining at the atomic scale. Proceedings of the Institution of Mechanical Engineers, Part B: Journal of Engineering Manufacture, 215 (12) (2001) 1639-1672

[4] S. Goel, W.B. Rashid, X. Luo, A. Agrawal, V. K. Jain, A theoretical assessment of surface defect machining and hot machining of nanocrystalline silicon carbide. Journal of Manufacturing Science and Engineering, 136 (2) (2014) 021015

[5] T-H Fang, C-I Weng, J-G Chang, Molecular dynamics analysis of temperature effects on nanoindentation measurement. Materials Science and Engineering A, 357 (2003) 7-12

[6] C-L Liu, T-H Fang, J-F Lin, Atomistic simulations of hard and soft films under nanoindentation. Materials Science and Engineering A 452-453 (2007) 135-141

[7] J-Y Hsieh, S-P Ju, S-H Li, C-C Hwang, Temperature dependence in nanoindentation of a metal substrate by a diamond-like tip. Physical Review B (2004) 70, 195424

[8] A. C. Lund, A. M. Hodge, C. A. Schuh, Incipient plasticity during nanoindentation at elevated temperatures. Appl. Phys. Lett. 85 (2004) 1362

[9] V. Domnich, Y. Aratyn, W.M. Kriven, and Y. Gogotsi: Temperature dependence of silicon hardness: experimental evidence of phase transformations. Rev. Adv. Mater. Sci. 17, $33(2008)$

[10] S. Goel, N. H. Faisal, X. Luo, J. Yan, A. Agrawal, Nanoindentation of polysilicon and single crystal silicon: Molecular dynamics simulation and experimental validation. J. Phys. D: Appl. Phys. 47 (2014) 275304

[11] W. B. Rashid, S. Goel, X. Luo, J. M. Ritchie, The development of a surface defect machining method for hard turning processes. Wear 302(2013)1124-1135

[12] Y. Dong, Q. Li, A. Martini, Molecular dynamics simulation of atomic friction: A review 
and guide. Journal of Vacuum Science \& Technology A 31(2013) 030801

[13] P. Erhart, K. Albe, Analytical potential for atomistic simulations of silicon, carbon, and silicon carbide. Physical Review B, 71(3) (2005) 035211

[14] P. M. Agrawal, L. M. Raff, R. Komanduri, Monte Carlo simulations of void-nucleated melting of silicon via modification in the Tersoff potential parameters. Physical Review B 72 (2006) 125206

[15] Tersoff, J., Modeling solid-state chemistry: Interatomic potentials for multicomponent systems. Physical Review B, 1989. 39(8): p. 5566.2

[16] Tersoff, J., Erratum: Modeling solid-state chemistry: Interatomic potentials for multicomponent systems. Physical Review B, 1990. 41(5): p. 3248

[17] Goel, S., et al., Influence of microstructure on the cutting behaviour of silicon. Acta Materialia, 2016. 105: p. 464-478.

[18] J. Belak, Nanotribology: modelling atoms when surfaces collide Energ. Tech. Rev. (1994), pp. 13-24

[19] N. Chandrasekaran, A. Noori Khajavi , L. M. Raff, R. Komanduri, A new method for molecular dynamics simulation of nanometric cutting. Philosophical Magazine Part B, 77:1, 7-26 (1998)

[20] R. Komanduri, N. Chandrasekaran, and L. M. Raff, Molecular dynamics simulation of atomic-scale friction. Phys. Rev. B 61, 14007 (2000)

[21] R. Komanduri , N. Ch and rasekaran \& L. M. Raff (2001) Molecular dynamics simulation of the nanometric cutting of silicon, Philosophical Magazine Part B, 81:12, 19892019.

[22] R. Komanduri, N. Chandrasekaran \& L. M. Raff (1999) Some aspects of machining with negative-rake tools simulating grinding: A molecular dynamics simulation approach, Philosophical Magazine Part B, 79:7, 955-968 
[23] S. Goel, X. Luo, R. L. Reuben, Molecular dynamics simulation model for the quantitative assessment of tool wear during single point diamond turning of cubic silicon carbide. Computational Materials Science 51 (2011) 402-408

[24] Y. Okada, Y. Tokumaru, Precise determination of lattice parameter and thermal expansion coefficient of silicon between 300 and 1500 K. J. Appl. Phys., 56 (2) (1984) 314320

[25] S. Plimpton, Fast parallel algorithms for short-range molecular-dynamics. Journal of computational physics, 117 (1) (1995) 1-19

[26] A. Stukowski, Visualization and analysis of atomistic simulation data with OVITO-the Open Visualization Tool Modelling Simul. Mater. Sci. Eng. 18 (2010), 015012

[27] Properties of Silicon, Emis Datareviews Series No. 4, edited by G. L. Harris (INSPEC, London, (1988)

[28] B. Lee, E. Rudd, First-principles study of the Young's modulus of $\mathrm{Si}<001>$ nanowires. Physical Review B 75, (2007) 041305 (R)

[29] M. Wang, W. Wang, Z. Lu, Anisotropy of machined surfaces involved in the ultraprecision turning of single-crystal silicon-a simulation and experimental study. Int $\mathbf{J}$ Adv Manuf Technol (2012) 60:473-485

[30] R. Al-Sayegh, C. Makatsoris, Vision-Augmented Molecular Dynamics Simulation of Nanoindentation. Journal of Nanomaterials, Article ID 857574

[31] F. Shimizu, S. Ogata, J. Li, Theory of Shear Banding in Metallic Glasses and Molecular Dynamics Calculations. Materials Transactions, 48 (11) (2007) 2923-2927

[32] S. Goel, S. Joshi, G. Abdelal, A. Agrawal, Molecular dynamics simulation of nanoindentation of $\mathrm{Fe}_{3} \mathrm{C}$ and $\mathrm{Fe}_{4} \mathrm{C}$. Materials Science \& Engineering A 597(2014) 331-341 [33] T. Shibata, S. Fujii, E. Makino, M. Ikeda, Ductile-regime turning mechanism of singlecrystal silicon. Precision Engineering 18 (1996) 129-137 
[34] V. Domnich, Y. Gogotsi, Phase transformations in silicon under contact loading. Rev.Adv. Mater.Sci 3 (2002) 1-36

[35] S. Goel, X. Luo, R. L. Reuben, Wear mechanism of diamond tools against single crystal silicon in single point diamond turning process. Tribology International 57 (2013) 272-281 [36] X. Yu, P. Raterron, J. Zhang, Z. Lin, L. Wang, Y. Zhao, Constitutive law and flow mechanism in diamond deformation, Sci. Rep. 2 (876) DOI: 10.1038/srep00876 (2012).

[37] A. Mussi, D. Eyidi, A. Shiryaev, J. Rabier, TEM observations of dislocations in plastically deformed diamond, Phys. Status Solidi A. 210 (2013) 191-194

[38] H. Chacham, L. Kleinman, Instabilities in diamond under high shear stress. Physical Review Letters 85(23) (2000) 4904-4907

\section{Appendix A}

Table 1A. Average forces and associated parameters while cutting silicon on different crystallographic orientations at various temperatures obtained by ABOP potential function

\begin{tabular}{|c|c|c|c|c|c|c|}
\hline Workpiece & Crystal & Average & Average & Average & Average & Average \\
temperature & orientation & tangential & thrust & resultant & specific & force ratio \\
& & cutting & force & force & cutting & \\
& & force $(\mathrm{nN})$ & $(\mathrm{nN})$ & $(\mathrm{nN})$ & energy & \\
\hline \multirow{3}{*}{300} & $(010)$ & 535.9 & 772.9 & 940.5 & 58 & 0.69 \\
\cline { 2 - 7 } & $(110)$ & 523.7 & 804.7 & 960.2 & 59.3 & 0.65 \\
\cline { 2 - 7 } & $(111)$ & 518.4 & 622.6 & 810.1 & 50 & 0.83 \\
\hline & $(010)$ & 489.6 & 720.6 & 871.2 & 53.8 & 0.68 \\
\hline
\end{tabular}




\begin{tabular}{|c|c|c|c|c|c|c|}
\hline \multirow[t]{2}{*}{500} & (110) & 513.7 & 758.6 & 916.2 & 56.5 & 0.67 \\
\hline & (111) & 463.6 & 558.8 & 726.1 & 44.8 & 0.83 \\
\hline \multirow{3}{*}{750} & $(010)$ & 470.4 & 675.2 & 822.9 & 50.8 & 0.69 \\
\hline & (110) & 448.1 & 720.6 & 848.6 & 52.4 & 0.62 \\
\hline & (111) & 437.5 & 518.4 & 678.3 & 41.9 & 0.84 \\
\hline \multirow{3}{*}{850} & $(010)$ & 459.9 & 653.3 & 798.9 & 49.3 & 0.7 \\
\hline & $(110)$ & 434.6 & 707.4 & 830.2 & 51.2 & 0.61 \\
\hline & $(111)$ & 417.8 & 505.6 & 655.9 & 40.5 & 0.82 \\
\hline \multirow{3}{*}{1173} & $(010)$ & 425.2 & 577.1 & 716.9 & 44.2 & 0.73 \\
\hline & $(110)$ & 418.2 & 663.2 & 784 & 48.4 & 0.63 \\
\hline & (111) & 389.7 & 472.3 & 612.3 & 37.8 & 0.82 \\
\hline \multirow{3}{*}{1500} & $(010)$ & 369.2 & 538.6 & 652.9 & 40.3 & 0.68 \\
\hline & $(110)$ & 378 & 644.9 & 747.5 & 46.1 & 0.58 \\
\hline & (111) & 320.9 & 311.2 & 446.9 & 27.6 & 1.03 \\
\hline
\end{tabular}

\section{Appendix B}

Table 1B. Stresses and temperatures in the cutting zone while machining silicon on different crystallographic orientations obtained by ABOP potential function

\begin{tabular}{|c|c|c|c|c|c|c|c|c|}
\hline Workpiec & Crystal & Von & Octahedr & Tresc & Minor & Major & Peak & Temperatu \\
e & orientati & Mise & al & a & princip & princip & temperatu & re at the \\
temperatu & on & $\mathrm{s}$ & stress & stress & al & al & re in the & onset of \\
re (K) & & stres & $(\mathrm{GPa})$ & $(\mathrm{GPa}$ & stress & stress & cutting & plastic \\
& & & & & $(\mathrm{GPa})$ & $(\mathrm{GPa})$ & zone $(\mathrm{K})$ & yielding \\
& & & & & & & & $(\mathrm{K})$ \\
\hline
\end{tabular}




\begin{tabular}{|c|c|c|c|c|c|c|c|c|}
\hline & & a) & & & & & & \\
\hline \multirow{3}{*}{300} & $(010)$ & 13.6 & 6.41 & 7.74 & -0.87 & -16.36 & 670.8 & 594.6 \\
\hline & $(110)$ & 12.8 & 6.08 & 7.12 & -1.95 & -16.2 & 677.7 & 607.5 \\
\hline & (111) & 14.5 & 6.87 & 8.38 & 3.14 & -13.63 & 663.1 & 562.8 \\
\hline \multirow{4}{*}{500} & $(010)$ & 12.5 & 5.93 & 7.16 & -0.53 & -14.85 & 780.1 & 708.5 \\
\hline & & 8 & & & & & & \\
\hline & (110) & 12.5 & 5.93 & 7.05 & -3.76 & -17.87 & 795.8 & 744.2 \\
\hline & (111) & 14.2 & 6.72 & 7.62 & 1.1 & -14.15 & 751.1 & 676 \\
\hline \multirow{4}{*}{750} & $(010)$ & 11.8 & 5.57 & 6.74 & -0.02 & -13.51 & 925.8 & 858.3 \\
\hline & & 5 & & & & & & \\
\hline & (110) & 12.4 & 5.87 & 6.95 & -0.38 & -14.29 & 971.4 & 908.1 \\
\hline & $(111)$ & 13.8 & 6.51 & 7.24 & -0.55 & -15.03 & 865.4 & 824.1 \\
\hline \multirow{5}{*}{850} & $(010)$ & 11.6 & 5.51 & 6.67 & -0.38 & -13.72 & 973.5 & 908.1 \\
\hline & & 9 & & & & & & \\
\hline & (110) & 12.5 & 5.92 & 7.06 & -0.88 & -15 & 1076.7 & 967.4 \\
\hline & (111) & 11.8 & 5.6 & 6.5 & 1.48 & -11.52 & 952.7 & 876.5 \\
\hline & $(010)$ & 11.9 & 5.64 & 6.74 & -2.44 & -15.93 & 1320.7 & 1152 \\
\hline
\end{tabular}




\begin{tabular}{|c|c|c|c|c|c|c|c|c|}
\hline \multirow[t]{3}{*}{1173} & & 6 & & & & & & \\
\hline & (110) & 12.5 & 5.9 & 7.13 & -0.65 & -14.91 & 1415.7 & 1223.2 \\
\hline & (111) & 9.97 & 4.7 & 5.57 & 1.9 & -9.25 & 1245.5 & 1094.9 \\
\hline \multirow{4}{*}{1500} & $(010)$ & 10.8 & 5.11 & 6.16 & 0.84 & -11.48 & 1618.3 & 1304.9 \\
\hline & & 5 & & & & & & \\
\hline & $(110)$ & 11.4 & 5.4 & 6.38 & -0.48 & -13.24 & 1781.7 & 1364.2 \\
\hline & (111) & 9.16 & 4.32 & 4.96 & 0.86 & -9.06 & 1593.6 & 1234.7 \\
\hline
\end{tabular}

\section{Appendix C}

Table 1C. Average stresses and temperature on the cutting edge of the diamond tool while machining silicon on different crystallographic orientations obtained by ABOP potential function

\begin{tabular}{|c|c|c|c|c|}
\hline \multirow{2}{*}{$\begin{array}{c}\text { Workpiece } \\
\text { temperature }\end{array}$} & $\begin{array}{c}\text { Crystal } \\
\text { orientation }\end{array}$ & $\begin{array}{c}\text { von Mises } \\
\text { stress on the } \\
\text { cutting edge } \\
(\mathrm{GPa})\end{array}$ & $\begin{array}{c}\text { Tresca stress } \\
\text { on the } \\
\text { cutting edge } \\
(\mathrm{GPa})\end{array}$ & $\begin{array}{c}\text { Temperature } \\
\text { on the } \\
\text { cutting edge } \\
(\mathrm{K})\end{array}$ \\
\hline \multirow{3}{*}{300} & $(010)$ & 25.2 & 14.1 & 347.5 \\
\cline { 2 - 5 } & $(110)$ & 25.8 & 14.6 & 347.7 \\
\hline \multirow{3}{*}{500} & $(111)$ & 24.4 & 13.9 & 337.4 \\
\cline { 2 - 5 } & $(110)$ & 24.4 & 14 & 351 \\
\cline { 2 - 5 } & $(111)$ & 23.9 & 13.4 & 346.1 \\
\hline
\end{tabular}




\begin{tabular}{|c|c|c|c|c|}
\hline \multirow{3}{*}{750} & $(010)$ & 24.8 & 13.7 & 370.6 \\
\cline { 2 - 5 } & $(110)$ & 23.1 & 13.4 & 366.6 \\
\cline { 2 - 5 } & $(111)$ & 22.7 & 12.1 & 356.8 \\
\hline \multirow{3}{*}{850} & $(010)$ & 24.1 & 13.7 & 382.3 \\
\cline { 2 - 5 } & $(110)$ & 22.9 & 12.6 & 379.1 \\
\cline { 2 - 5 } & $(111)$ & 22.2 & 12 & 365.3 \\
\hline \multirow{3}{*}{1173} & $(010)$ & 18.8 & 10.8 & 406.7 \\
\cline { 2 - 5 } & $(110)$ & 19 & 10.7 & 399.4 \\
\cline { 2 - 5 } & $(010)$ & 18.6 & 10.5 & 410 \\
\hline \multirow{3}{*}{1500} & $(110)$ & 18.6 & 10.6 & 413.1 \\
\cline { 2 - 5 } & $(111)$ & 18.1 & 10 & 375 \\
\cline { 2 - 5 } & & & & \\
\hline
\end{tabular}

